\title{
Pesquisando na interface: problemas e desafios a partir da pesquisa qualitativa em saúde
}

Helen Gonçalves(a) Renata Menasche ${ }^{(b)}$

Gonçalves $\mathrm{H}$, Menasche $\mathrm{R}$. Researching at the interface: problems and challenges from qualitative health research. Interface (Botucatu). 2014; 18(50):449-56.

There is a growing interest concerning the use of methodological procedures of qualitative research in various areas of knowledge where this kind of investigation was traditionally uncommon. Within healthcare, the importance of qualitative research for understanding health and disease processes is recognized. However, its credibility has been questioned, correlated with negligent use of qualitative approaches, such as the reduction of theoretical and methodological relevance. This misuse is most often noticed in publications in which a qualitative approach is used as a tool kit. Simultaneously, the institutions' requirement that researchers should increase their productivity has forced them to review broader aims in their analysis and writing. Looking at a group or context requires a theoretical and methodological tool, in order to make inferences and to propose theoretical breakages and/or to demonstrate new points in relation to known topics.

Keywords: Qualitative research. Theoretical-methodological approach. Social theory. Scientific production.
Há crescente interesse e emprego de procedimentos metodológicos característicos da pesquisa qualitativa por diversas áreas do conhecimento que tradicionalmente não eram comuns. $\mathrm{Na}$ área da saúde, é reconhecida a importância da pesquisa qualitativa para a compreensão dos processos saúde-doença. Sua credibilidade tem sido questionada em vários âmbitos e relacionada a usos negligentes da abordagem qualitativa, como reduzir a relevância teórico-metodológica à aplicação de técnicas. O mau uso é mais frequentemente notado nas publicações quando a abordagem qualitativa é utilizada enquanto um kit de ferramentas. Simultaneamente, o "produtivismo" exigido pelas instituições tem obrigado os pesquisadores a rever objetivos mais amplos de análise/escrita. O olhar sobre um grupo/contexto requer um aparato teórico-metodológico, de modo a possibilitar inferir algo e propor rupturas teóricas e/ou evidenciar novos pontos sobre um tema conhecido.

Palavras-chave: Pesquisa qualitativa. Abordagem teórico-metodológica. Teoria social. Produção científica.

\footnotetext{
(a) Programa de Pós-Graduação em Epidemiologia, Universidade Federal de Pelotas (UFPEL). Rua Marechal Deodoro, $1160,3^{\circ}$ andar. Pelotas, RS, Brasil. 96020-220. hdgs.epi@gmail.com

(b) Programa de Pós-Graduação em Antropologia, UFPEL. Pelotas, RS, Brasil. renata.menasche@ pq.cnpq.br
} 


\section{Introdução}

Este texto, em sua primeira versão, compôs a discussão iniciada durante o VI Congresso Nacional de Ciências Sociais e Humanas em Saúde (Rio de Janeiro, 2013), na mesa que teve por tema "Usos e Abusos da Pesquisa Qualitativa em Saúde". Naquele momento, foram comentados alguns dos problemas e dificuldades do processo de pesquisa a partir da abordagem qualitativa, tendo sido mencionados, entre outros: a produção textual, o incipiente diálogo com as teorias, e as razões mais frequentes de negativas das revistas quando da submissão de artigos para publicação.

Este trabalho, seguindo a reflexão sobre os incômodos e abusos (equívocos teórico-metodológicos) na pesquisa qualitativa em saúde, coloca-se como continuidade daquele debate, mas concentrandose, especificamente, em problemas detectados a partir da leitura de artigos e processo de pesquisa e/ ou escrita de artigos. Deve ser interpretado quase como um desabafo, no esforço de compartilhar, com colegas, inquietações decorrentes de nossas inserções e experiências de pesquisa e orientação de estudantes, caracterizadas por temas e projetos marcados pela interface da antropologia com outras áreas do conhecimento - especialmente a saúde -, de tradições de pesquisa muito distintas.

Não nos deteremos, assim, em discutir como integrar a abordagem qualitativa às perguntas de pesquisa e vice-versa. Para isso, recomendamos alguns livros e artigos que, decorrentes de pesquisa do tipo, possibilitam uma boa apreensão dessas questões ${ }^{1-5}$. Citaremos, rapidamente, alguns exemplos de usos da pesquisa qualitativa em saúde, assim, teremos uma pequena amostra das possibilidades de investigação no campo. Uma gama de estudos de abordagem qualitativa na área aprofundam as razões pelas quais dado grupo de indivíduos mantém determinado comportamento considerado inapropriado à saúde, como: fatores que influenciam na não-adesão a tratamento medicamentoso ou alimentar, impacto da política de redução de danos sobre usuários de drogas ilícitas, razões para o uso irregular ou não-uso de preservativos em relações sexuais. Há, ainda, a possibilidade de a pesquisa qualitativa dar suporte a investigações com grandes amostras, interagindo com estudos "quantitativos", entre outras: (a) indicando modos de abordar, nos questionários, tema específico antes não considerado definidor para alguns comportamentos, usando, no instrumento, o linguajar local, sugerindo categorias de respostas mais apropriadas; (b) apontando como os fatores socioculturais podem influenciar os serviços de saúde; (c) explorando, posteriormente, como as associações estatísticas podem ser mais bem compreendidas quando o contexto social ganha vida; (d) avaliando programas ou serviços de saúde e como processos sociais interferem em ambos; (e) demonstrando como as ideias de causalidade divulgadas pela mídia são apreendidas e se refletem em comportamentos em saúde. No entanto, ainda que a pesquisa qualitativa traga grande contribuição para a compreensão de processos saúde-doença e sua importância seja cada vez mais reconhecida na área, nem todos os trabalhos publicados demarcam a relevância teórico-metodológica inerente a sua abordagem. Nossa preocupação se assenta, inicialmente, nesse ponto. É o diálogo entre teoria e método que confere sentido aos 'dados', isto é, às racionalidades ou lógicas médicas, à experiência da doença e às lógicas histórico e socioculturais das várias instituições, por exemplo. Assim sendo, entre aqueles que usam indevidamente a abordagem qualitativa, é comum negligenciar a contextualização de relações hierárquicas e situacionais, descritas/apontadas por seus interlocutores e, a partir deles, trazidas aos textos sem que o pesquisador construa e medeie tais relações a partir do diálogo com seu aporte teórico: ele apenas '(re)produz' no texto a fala do interlocutor.

Nesse quadro, não é de surpreender que a qualidade de publicações identificadas como de estudos qualitativos venha sendo alvo de críticas e descrédito entre profissionais da área da saúde coletiva. No entanto, apesar de sua constância e consequências, é incomum que ocorra, publicamente, a formalização dessas constatações e, menos ainda, um debate aberto e autocrítico, com o intuito de contornar problemas entre profissionais de diferentes áreas, incluindo a da saúde. É importante ter claro e afirmar: ao pesquisador não cabe apenas o papel de transcritor ${ }^{6-8}$.

Neste trabalho, as críticas aos abusos serão demarcadas em dois pares de categorias: teoria/técnica e tempo/desafio. Para ambas, demarcamos alguns aspectos que podem contribuir para sua ocorrência. Os aspectos escolhidos não pretendem esgotar o tema e talvez sequer sejam os mais importantes, mas se mostraram mais visíveis em nosso cotidiano. 
(c) A título de exemplo, ver: http://www. equator-network.org/ reporting-guidelines

\section{Fala como resultado e teoria na referência}

Não é de estranhar que, para superar possíveis falhas na divulgação de resultados de pesquisas, algumas revistas internacionais disponibilizem guidelines (parâmetros) para que o artigo seja um texto e possua elementos suficientes para os leitores, atendendo à disciplina e a critérios científicos. Vários exemplos desses guias podem ser encontrados, em sites de busca, a partir dos termos guidelines and $\mathrm{OR}$ for qualitative studies ${ }^{(c)}$. Algumas críticas a eles apontam o risco do engessamento, entendendo que os parâmetros adotados acabam por enquadrar os estudos em tradições positivistas, sufocando os aspectos interpretativos e criativos da pesquisa qualitativa ${ }^{9}$. As discordâncias podem ser didáticas e desafiadoras, daí vale a pergunta: como evitar o inadequado? Se a resposta for "depende", certamente estará correta, porque, de fato, precisamos sempre pensar e criticar conforme o estudo, sem jamais desconsiderar os engodos do método ${ }^{10}$. Mas como avaliar a adequação diante da diversidade? Como o leitor especialmente o que possui outra formação, não na área das ciências sociais, poderá apreender se o estudo abusou ou não? Como um aluno poderá apreender que o estudo falhou em vários sentidos? Voltamos a alguns pontos importantes, que merecem ser constantemente adequados aos temas de pesquisa. Essa possibilidade de constante adequação traz consigo a riqueza da abordagem, assim como sua fragilização, quando da utilização indevida.

O problema do abuso ou mau uso é que, muitas vezes, ele não é fácil de ser medido ou mesmo detectado na redação dos resultados. Um estudo pode estar bem descrito e ter interpretações interessantes, mas não há garantias de que os procedimentos naquela situação tenham sido realizados com sucesso. Ou seja, em pesquisa qualitativa, as interpretações contemplam uma postura coerente do pesquisador entre teoria (que orienta a interação) e método (procedimentos para chegar à compreensão) em todo o processo do estudo, ambos entendidos como partes do mesmo social.

Pesquisadores mais experientes podem perceber quando um texto está incompleto ou julgar que as interpretações estão desconectadas das falas selecionadas, entre outras tantas possibilidades. Há, ainda, a chance disso não ocorrer. Portanto, não estão totalmente claros todos os juízos necessários para uma avaliação do processo de pesquisa, e não é sem razão que não encontramos checklists para a publicação de estudos qualitativos em revistas de Antropologia, entre outras. É bastante provável que alguns abusos estejam somente vinculados ao pouco aprofundamento teórico-metodológico, visto que há muitos profissionais com conhecimentos teóricos e práticos distintos trabalhando com base nessa abordagem. Nessa ampla utilização, percebemos, ao circular por diferentes ambientes acadêmicos, que a importância dada ao método está, em grande parte, deslocada do estudo das teorias sociais ou socioantropológicas que fundamentam o olhar "qualitativo" e a possibilidade de interpretação do social.

Esse olhar, que nasce pelo interesse nas teorias sociais e culturais, nem sempre justifica a escolha profissional pela abordagem qualitativa. Há "pesquisadores qualitativos" que se reconhecem como tal por entenderem que são inábeis em lidar com números/cálculos. Nesses casos (e em outros), as questões históricas e socioculturais passam ao largo de fases importantes do processo de pesquisa - podendo ser notadas desde a confecção do projeto. As referências teóricas são apenas citadas entre parênteses, estão incompletas e/ou desatualizadas no item final da redação. A quantidade de publicações com essas características é exemplar das disparidades desses problemas na academia e dos critérios de 
escrita e de avaliação de um artigo baseado em pesquisa qualitativa entre revisores. Isto, podemos afirmar, não ocorre somente na área da saúde.

Vale questionar, portanto, que tipo de contribuição os profissionais que trabalham com a pesquisa qualitativa nessa área têm ofertado ao conhecimento, sempre limitado ${ }^{10}$. Muitos estudos realizados por pesquisadores em antropologia do corpo e da saúde dialogaram com indicadores de saúde. Desse modo, as perguntas respondidas pelas pesquisas qualitativas pretendiam preencher lacunas do conhecimento atual sobre o que ocorre com dado grupo de pessoas em seu contexto ou como um comportamento/estilo de vida foi problematizado na saúde. Mas o desvelamento das lógicas do grupo, forma de entendimento de como o social molda e influencia os comportamentos, nem sempre é encontrado nessas publicações. Se invariavelmente o fizessem, relativizariam, questionariam e, assim, novas hipóteses seriam levantadas, em alguns casos, ações em saúde constituiriam propostas. Todas essas questões podem se complicar positivamente com interesse sobre o tema pesquisado.

Ainda, são usos legítimos se o conjunto de informações coletadas e interpretadas e a estrutura teórica se suportam ${ }^{11,12}$. No entanto, boa parte dos estudos na área da saúde, ao explicitar somente as falas de interlocutores, se reduz a apontar crenças sobre doenças. As tendências teóricas que, de fato, possam ter norteado a escolha do método empregado, o referencial do pesquisador e suas influências nas interações e interpretações são relegadas a frases, ou estão fora dos textos. Caracterizaria um abuso ter parte desse processo realizado?

Saber a quais perguntas a pesquisa qualitativa responde não configura um conhecimento teórico suficiente para o manejo do processo de pesquisar - necessário, mas não suficiente e, ainda menos, único. Optar pelo "quali" não garante que a fala por si seja apreendida em sua dimensão histórica e social, e que a compreensão de tudo estará garantida: pode apenas constituir uma hipótese a se confirmar em 'campo'.

A evidência da narrativa por si só não deve ser encarada como sinônimo de pesquisa qualitativa. Sem generalizar, vimos muitos resultados com uma quantidade de depoimentos pincelados das narrativas considerados como autoexplicativos, abusando da densidade ateórica. Como o mau uso não inviabiliza publicações, conforme salientado, a pesquisa qualitativa tem, igualmente, sido compreendida como sinônimo de conversa com "informantes", cujos resultados apontam para o exótico (associações inesperadas), denotando diferenças entre o senso comum e o conhecimento científico. Na pesquisa antropológica, mais especificamente na discussão sobre o método etnográfico - que emprega, enquanto técnicas de pesquisa: observação participante, entrevistas semiestruturadas, conversas em grupo, entre outras -, é central a reflexão sobre a relação entre "pesquisador" e "pesquisado". A relação dialógica buscada implica mais comumente a utilização, pelos antropólogos, do termo "interlocutor", em detrimento de "informante", empregado por outros em situação de pesquisa de "mão única", em que o pesquisador se utiliza da entrevista para a obtenção de informações, em um processo extremamente limitado de interação ${ }^{13}$.

Em razão da densidade ateórica, há acadêmicos que acreditam que esse tipo de pesquisa é "aquela" que se caracteriza por não precisar de "muitos informantes", logo, mais rápida e fácil. Assim sendo, focar mais as falas do que os determinantes sociais de sua produção e comportamentos é prática corrente nesse grupo, descaracterizando um estudo "qualitativo". Guardadas as limitações das áreas e do conhecimento, o mau uso publicado ou aceito nas universidades abre a possibilidade para que qualquer pessoa acredite fazer pesquisas qualitativas.

Encontramos essa forma de apresentação de dados mais comumente nas seguintes situações: quando os estudos são realizados por profissionais de saúde - mas não apenas esses, também ocorre em outras áreas, como as agrárias, por exemplo - que entendem o "quali" como um kit de ferramentas deslocado do processo histórico que fortaleceu teorias e método, e em pesquisas cujos resultados são apresentados quantitativamente (listados basicamente por sua recorrência e com interpretações que não vão além do que a fala mostra). A popularidade desse tipo de pesquisa trouxe, em muitos casos, equívoco teórico-metodológico.

Algumas origens dos usos incorretos foram mencionadas, assim como o que as promove. Profissionais atentos podem minimizar ou disseminar as considerações necessárias para estudos qualitativos. A apresentação minuciosa dos problemas mais frequentes que impedem os estudos 
qualitativos de serem publicados - ver o texto de Knauth publicado neste volume -, demonstra que essa preocupação já tem repercutido na avaliação dos trabalhos. Mas, não há a possibilidade de controle que abarque tudo o que é produzido e todas as edições de revistas, já que nem mesmo na área quantitativa - em que números alterados podem ser descobertos - isso é possível.

\section{Tempo e "produção" em pesquisa: desafio atual}

Os financiamentos para as pesquisas pelas agências de fomento nacionais cobram, dos contemplados, um cronograma de atividades que finde, em geral, em dois anos. Após a confecção do projeto aprovado, um esforço grande será requerido ao pesquisador para que, ao final, consiga produzir um relatório com análises nem tão preliminares. Acreditamos que exigências desse tipo concorram para dificultar ou, mesmo, inviabilizar alguns tipos de pesquisa qualitativa, especialmente etnografias, com ou sem financiamento. Profissionalismo, convicção e paixão o manterão nos objetivos. Os desavisados podem acreditar que os dois anos sejam suficientes. Pesquisadores com formação em antropologia ou ciências sociais, por exemplo, sabem que o trabalho de campo ganha densidade quanto maior for a sua inserção no contexto de pesquisa. Nessa interação há uma série de barreiras da vida cotidiana que podem aumentar o período de imersão em campo. O tempo de pesquisa tende a ser aumentado, e não reduzido. A imersão nesse processo estimula novas perguntas, amplia a compreensão sobre o tema em questão e aumenta o tempo de pesquisa e análises. A necessidade constante de dialogar teoria e método, pergunta/objeto e método-teoria, grupo e tema/revisão sobre o assunto irá minimizar os abusos que muitos de nós criticamos. O que estamos produzindo e para quem são questões fundamentais.

Todavia, apesar das pressões para cumprimento de prazo, é possível, em algum sentido, atingir objetivos se o método se adequar àquele tempo e responder à pergunta de pesquisa, mas dificilmente sem muito esforço. Traremos um exemplo com problemas para chegar a outro ponto dos abusos. Há cursos de graduação e especialização que exigem de seus alunos, para conclusão de curso, um trabalho de pesquisa em saúde. Os estudos qualitativos são, nesse momento, bastante privilegiados, o que não seria em si um problema, não fosse pelo fato de, muitas vezes, serem imaginados como mais fáceis, porque 'não exigem cálculos'.

Um fato ocorrido com uma de nós pode ser tomado como emblemático para uma autocrítica. Uma aluna de especialização solicitou orientação, já em uma fase adiantada de seu curso. Estava angustiada, não imaginara não ser possível receber apoio técnico, teórico-metodológico no grupo do curso. $\mathrm{O}$ tema era interessante e contemplava os requisitos tanto de uma pesquisa qualitativa quanto da área de seu curso. A construção do projeto deveria ser imediata, com pouco prazo para sua conclusão. Com muita vontade de aprender e fazer correto, conseguimos produzi-lo.Sua ideia era descobrir as dúvidas e impedimentos de pacientes para conversar com médicos sobre sexualidade/sexo/relações sexuais durante tratamento quimio ou radioterápico. Buscar o que a literatura aponta e com quem dialogar foi, então, a primeira orientação. No pouco tempo em campo, com tempo limitado para realizá-lo, a estudante conversou com todos pacientes que receberam tratamento para câncer (em estágios distintos de tratamento e doença) em um dia específico da semana. Conversou, assim, com trinta pessoas em tratamento, de ambos os sexos e idades variadas e, ainda, com alguns médicos que se dispuseram a recebê-la. Ela descobriu, durante o tempo de convívio com os doentes, que o constrangimento é grande, assim como as dúvidas. Anotou todas, indagou sobre o que seus médicos diziam e, ao fim, elaboramos um artigo, para sua defesa. Ela havia feito uma pequena revisão da literatura, pois são poucos os artigos publicados no Brasil sobre o tema, havendo mais material na literatura internacional, cujo acesso era prejudicado pela dificuldade de ler em outra língua. Diante da riqueza dos dados, da vontade de aprender e das condições dadas, como fazer algo mais denso? Ainda que a confecção de um artigo sem tanta densidade teórica não tenha sido barreira para a conclusão do curso e, tampouco, que tal limitação a tivesse impedido de formular perguntas e encontrar respostas para quem se encontrava em tratamento, se pode apontar que a impossibilitou o olhar e a escuta apurados, às entrelinhas dos diálogos, aos silêncios, aos valores morais. Sendo assim, falhamos!? Outras assertivas e ligações explicativas ou novas conclusões foram tolhidas pelas limitações apontadas. 
Caracterizaríamos tal exemplo como abuso ou uso limitado do método? Até então, vínhamos caracterizando tais estudos como abusos. O que mudou? Pouco e muito. Pouco no que diz respeito ao resultado - que foi basicamente descritivo. Ao fim do trabalho, construímos um folder explicativo, no modelo perguntas e respostas, sobre ter ou não relações sexuais durante tratamento. $O$ folder incluía as dúvidas apontadas no estudo e estaria disponível aos pacientes do serviço de oncologia. Mas também muito, porque foi o caminho mais rápido e metodologicamente afinado com as necessidades de um estudo qualitativo e com uma redução em sua possibilidade de interpretação das dúvidas, da relação com a instituição, corpo e doença - entre outros aspectos. A ideia inicial da aluna, fomentada por seu aprendizado no local sobre a abordagem qualitativa, era somente elaborar um questionário com perguntas abertas sobre as dúvidas dos entrevistados. Nesse caso, estamos contextualizando, resumidamente, a situação, em outros não temos acesso à história. Se considerarmos um abuso, cabe evidenciar o papel dos pesquisadores enquanto professores ou tutores de alunos e que essa prática tem sido mais frequente do que se imagina. Nesse contexto, há que se levar em conta que, ainda que haja exceções - casos de pesquisadores muito ocupados que são particularmente perspicazes para captar, a qualquer instante, incoerências em um processo de pesquisa -, comumente professores mais experientes, que possuem projetos maiores, também são os mais atarefados com as atividades acadêmicas (aulas, orientações, congressos, palestras, reuniões) e, por isso, podem ter menos tempo para um olhar mais atento aos trabalhos de seus alunos. E é preciso ter claro que a falta dessa atenção, por essa ou outras razões, cobra seu preço na qualidade do que é produzido.

Além desses aspectos, que dizem respeito a demandas de toda ordem, há a cobrança crescente dos programas de pós-graduação, para que a produção acadêmica dos professores pesquisadores se amplie e que seja concretizada, quando em artigo, em revistas bem conceituadas (ver, por exemplo: Castiel e Sanz-Valero ${ }^{14}$; Sguissardi ${ }^{15}$; Trein e Rodrigues ${ }^{16}$ ). A qualidade do que é produzido certamente não é imune ao chamado 'produtivismo acadêmico', visto que desconsidera que trabalhos decorrentes de pesquisa qualitativa, especialmente de tipo etnográfico, demandam mais tempo.

Ainda, para dar conta das inúmeras atividades demandadas, é comum a muitos pesquisadores coordenarem equipes, que os auxiliam a realizar o trabalho de campo. Mas que tipo(s) de problema(s) decorre $(m)$ da distância entre o pesquisador mais experiente e o campo? As consequências (positivas e/ou negativas) dessa prática poderiam ser objeto de outro artigo: limitamo-nos, neste momento, a apontar a questão, como um dos elementos a serem discutidos.

\section{Considerações finais}

Muitos dos usos e abusos ocorridos se devem, paradoxalmente, à valorização das técnicas qualitativas por áreas outras que as das ciências humanas e sociais. Todavia, para responder às indagações científicas, o instrumental metodológico a ser empregado só produzirá respostas se teoria e técnica não forem dissociadas. Saber aplicá-la e interpretá-la à luz de categorias teóricas requer mais que compreender como um grupo focal se constitui e o que responde. A constante reafirmação de um campo de domínio e de características do pesquisador não significa, aqui, ode à endogenia. $\mathrm{A}$ compreensão de que a pesquisa qualitativa pode ter grande abrangência na área da saúde e que usada por diferentes profissionais enriquecerá o conhecimento de todos é positiva. No entanto, pesquisar não é somente aplicar técnicas e métodos. Para que o crescimento teórico-metodológico seja possível e interessante a todos, precisamos ser capazes de autocrítica e, não apenas, tentar aproximações que resultem em destacar as diferenças práticas entre as ciências, há muito conhecidas. Gerar uma compreensão alargada de saúde-doença como processo social não é simples, menos, ainda, dialogar entre áreas.

O tempo e a resposta ao tempo, ao campo, precisam ganhar em conteúdo. Se existem pesquisas abusivas, qual é nosso papel? A ciência acontece com um olhar sobre um grupo/contexto/realidade, e esse olhar requer um aparato teórico-metodológico para inferir algo e propor rupturas teóricas e/ ou evidenciar novos pontos sobre um tema conhecido. Como bem resumiram Gomes e Silveira ${ }^{17}$, no exercício metódico de fazer pesquisa, a técnica é requisitada, contudo esse fazer está atrelado à base 
ontológica (teoria, método e técnica). Na área da saúde, a interface entre teoria e método faz com que os cuidados com a pesquisa qualitativa precisem ser reivindicados e praticados constantemente.

\section{Colaboradores}

HG redigiu a primeira versão do artigo e RM realizou a revisão crítica do manuscrito.

\section{Referências}

1. Victora CG, Knauth DR, Hassen MNA. Pesquisa qualitativa em saúde: uma introdução ao tema. Porto Alegre: Tomo Editorial; 2000.

2. Patton MQ. Qualitative research and evaluation methods. 3a ed. Califórnia: Sage; 2001.

3. Deslandes SF, Cruz Neto O, Minayo MCS, organizadores. Pesquisa social: teoria, método e criatividade. 21a ed. Petrópolis: Vozes; 2002.

4. Minayo MCS. O desafio do conhecimento: pesquisa qualitativa em saúde. $6 a$ ed. São Paulo: Hucitec; 2007.

5. Flick U. Coleção pesquisa qualitativa. Porto Alegre: Penso; 2011.

6. Da Matta R. O ofício do etnólogo, ou como ter "anthropological blues". In: Nunes EO, organizador. A aventura sociológica: objetividade, paixão, improviso e método na pesquisa social. Rio de Janeiro: Zahar; 1978. p. 23-35.

7. Durham ER. A pesquisa antropológica com populações urbanas: problemas e perspectivas. In: Cardoso RCL. organizador. A aventura antropológica: teoria e pesquisa. Rio de Janeiro: Paz e Terra; 1986. p. 17-37.

8. Cardoso R. Aventuras de antropólogos em campo ou como escapar das armadilhas no método. In: Cardoso RCL, organizador. A aventura antropológica: teoria e pesquisa. Rio de Janeiro: Paz e Terra; 1986. p. 95-105.

9. Chapple A, Rogers A. Explicit guidelines for qualitative research: a step in the right direction, a defence of the 'soft' option, or a form of sociological imperialism? Fam Pract. 1998; 15(6):556-61.

10. Fonseca C. Quando cada caso não é um caso. Pesquisa etnográfica e educação. Rev Bras Educ. 1999; (10):58-78.

11. Malinowski B. Argonautas do Pacífico Ocidental: um relato do empreendimento e da aventura dos nativos nos arquipélagos da Nova Guiné Melanésia. São Paulo: Abril Cultural; 1976.

12. Geertz C. A interpretação das culturas. Rio de Janeiro: LTC; 1989.

13. Cardoso de Oliveira R. O trabalho do antropólogo: olhar, ouvir, escrever. In: Cardoso de Oliveira R. O trabalho do antropólogo. 2a ed. São Paulo: Unesp; 2000. p. 17-35. 
14. Castiel LD, Sanz-Valero J. Entre fetichismo e sobrevivência: o artigo científico é uma mercadoria acadêmica? Cad Saude Publica. 2007; 23(12):3041-50.

15. Sguissardi V. Centralidade da Pós-Graduação e produtivismo acadêmico. In: Sguissardi V, Silva Júnior JR, organizadores. Trabalho intensificado nas federais: pós-graduação e produtivismo acadêmico. São Paulo: Xamã; 2009. p. 191-232.

16. Trein E, Rodrigues J. O mal-estar na academia: produtivismo científico, o fetichismo do conhecimento-mercadoria. Rev Bras Educ. 2011; 16(48):769-92.

17. Gomes MHA, Silveira C. Sobre o uso de métodos qualitativos em Saúde Coletiva, ou a falta que faz uma teoria. Rev Saude Publica. 2012; 46(1):160-5.

Gonçalves H, Menasche R. Investigación en interfaz: problemas y desafíos a partir de la investigación cualitativa en salud. Interface (Botucatu). 2014; 18(50):449-56.

Hay un interés creciente en el empleo de procedimientos metodológicos de la investigación cualitativa por parte de diversas áreas del conocimiento. En la salud se reconoce la importancia de la investigación cualitativa para la comprensión de los procesos salud-enfermedad. Todavia su credibilidad se ha puesto en tela de juicio en varios ámbitos y se relaciona a usos negligentes del abordaje cualitativo, tal como reducir la relevancia teórico-metodológica a la aplicación de técnicas. El mal uso se observa más frecuentemente en las publicaciones cuando se utiliza el abordaje cualitativo como un conjunto de herramientas. Al mismo tiempo, el "productivismo" exigido por las instituciones ha obligado a los investigadores a revisar objetivos más amplios de análisis/ escritura. La mirada sobre un grupo/contexto requiere un aparato teórico-metodológico para inferir algo y proponer rupturas teóricas y/o poner en evidencia nuevos puntos sobre un tema conocido.

Palabras clave: Investigación cualitativa. Abordaje teórico-metodológico. Teoría social. Producción científica. 